\title{
O PROTAGONISMO DA MULHER E SUA REPRESENTATIVIDADE NO DESENVOLVIMENTO LOCAL DA AGRICULTURA FAMILIAR
}

\author{
THE ROLE OF WOMEN AND THEIR REPRESENTATIVENESS IN \\ THE LOCAL DEVELOPMENT OF FAMILY FARMING
}

Albina Graciéla Aguilar Meus* ORCID: https://orcid.org/0000-0001-9383-8352

Luciana Zago Ethur** ORCID: https://orcid.org/0000-0001-6664-8326

\section{Resumo}

O estudo se propôs a analisar o trabalho reprodutivo e produtivo das agricultoras familiares no município de Itaqui-RS e seu impacto na geração de renda das famílias. Buscou-se destacar o trabalho das mulheres na agricultura e o protagonismo negado, avaliando e expondo o seu papel no desenvolvimento local. A metodologia utilizada foi baseada em uma pesquisa qualitativa de caráter descritivo. A pesquisa foi realizada com doze agricultoras feirantes e as entrevistas foram realizadas no ambiente da feira do agricultor. Constatou-se o importante papel no desenvolvimento local através do trabalho das mulheres na agricultura familiar, tanto nas atividades reprodutivas como produtivas. Portanto, fica evidente que as agricultoras, através do seu trabalho e na sua atuação nas mais diversas esferas sociais, protagonizam o desenvolvimento local da agricultura familiar.

Palavras-chave: Mulheres no campo; Representação social; Agricultoras familiares; Divisão sexual do trabalho.

\begin{abstract}
This study aimed to analyze the reproductive and productive work of female family farmers of Itaqui-RS and its impact on the income generation of families. It sought to highlight the work of women in agriculture and the denial of their role, evaluating and demonstrating their contribution to local development. The methodology was based on qualitative research with descriptive approach. It was carried out with twelve female farmers and the interviews were conducted in the agricultural product fair. The important role in local development was found through the work of women in family farming, both in reproductive and productive activities. Therefore, it is evident that female farmers, through their work and their performance in the most diverse social spheres, play a leading role in the local development of family farming.
\end{abstract}

Keywords: Women in the countryside; Social representation; Female family farmers; Sexual division of labor. 


\section{Introdução}

A agricultura familiar é considerada um espaço dinâmico e heterogêneo que se dá pela diversificação social-produtiva. Balestrin (2010) conceitua agricultura familiar como uma forma de reprodução que tem sua base no trabalho, no qual a família é responsável pela atividade agrária desenvolvida em pequenas propriedades. Em uma análise histórica na divisão sexual do trabalho na agricultura de base familiar, percebe-se que as mulheres, ao longo dos tempos, tiveram seu trabalho muitas vezes invisibilizado e subjugado, descrito apenas como um trabalho de reprodução, sem o devido reconhecimento ao seu trabalho produtivo. Esse contexto encontra-se fortemente marcado em função da diferenciação entre homens e mulheres, voltado apenas ao reconhecimento e à valorização do trabalho do homem (BRUMER; DOS ANJOS, 2008).

As relações de gênero são um dos fatores que estão no cerne das desigualdades. Ser mulher estabelece uma posição de coadjuvante tanto nas relações de trabalho quanto de renda, o que contribui para que os termos mulher e agricultora se tornem unívocos, remetendo apenas à identidade biológica (mulher), invisibilizando a profissional. Com isso, alguns autores como Nierdele et al. (2014) têm ressaltado o protagonismo das mulheres agricultoras que atuam como agentes ativas na produção e geração de emprego e renda, tendo surgido movimentos reivindicando políticas diferenciadas para o desenvolvimento rural.

Em definição, Brumer e Paulilo (2004) explicam que sexo é categoria biológica dada ao homem e à mulher, e a noção de gênero se constitui socialmente, atribuindo-se diferentes papéis a ambos os sexos. Alves et al. (2018), em seu estudo, infere que, na maioria das vezes, as mulheres rurais sequer são consideradas agricultoras, sendo conhecidas como mulher ou a filha de determinado agricultor, na total certeza da invisibilidade de sua contribuição financeira, com seu trabalho no campo. Outro ponto importante apontado por Herrera (2019) descreve que as mulheres sempre trabalharam, mas raramente suas atividades realizadas no núcleo familiar foram vistas como um trabalho, sendo comum ser reconhecido e descrito como mera ajuda aos pais e cônjuges.

Neste contexto, busca-se construir uma identidade de gênero na qual as mulheres sejam reconhecidas de forma equitativa por seu trabalho, nas diversas esferas sociais. No meio rural, o seu reconhecimento enquanto agricultora, dando-se visibilidade ao seu trabalho na agricultura, restituindo o mérito do seu trabalho e sua contribuição não apenas na reprodução, mas também na produção da geração da renda familiar.

Herrera (2017), em sua contextualização, explica as definições do trabalho produtivo e reprodutivo. $\mathrm{O}$ trabalho produtivo está associado à esfera pública e o reprodutivo está vinculado ao âmbito familiar, limitado à esfera privada, ao núcleo da família. Embora a figura da mulher esteja ligada ao trabalho reprodutivo, não significa que ela não desempenha um trabalho produtivo; ao contrário, no meio rural, por muitas vezes, não existe o reconhecimento, por parte da sociedade, o que está intrínseco ao patriarcalismo. A desvinculação dos substantivos mulher e agricultora se fazem importantes, e os termos necessitam ser complementares, conferindo identidade enquanto mulher e profissional. 
O desenvolvimento do presente trabalho se justifica por haver poucos estudos que abordam o tema relacionado à representatividade das mulheres agricultoras na região da fronteira oeste do Rio Grande do Sul. O cenário da agricultura familiar na região em estudo pode ser caracterizado como marginalizado e se deve a fatores históricos, sociais, políticos, culturais e econômicos.

A agricultura e economia do município sempre estiveram atreladas à produção extensiva. Primeiro, esses campos foram ocupados por gado vagante dos índios minuanos e charruas; mais tarde, os jesuítas passaram a utilizar as terras com o mesmo propósito. A criação de gado extensiva sempre foi favorecida pelas pastagens rasteiras, o que Pillar et al. (2007) classificam como vegetação campestre do sul do Brasil, composta por campos sulinos, que abrangem dois biomas (Pampa e Mata Atlântica), sendo que a metade sul do Estado do Rio Grande do Sul é o bioma Pampa. A vegetação sempre foi um fator determinante que fez com que a pecuária fosse a principal fonte econômica do município, desde sua fundação, porém, mais tardiamente, foi introduzida a monocultura orizícola, favorecida pelo tipo de solo em áreas de várzea (terras baixas) (CERETTA, 2014).

Neste contexto histórico, a agricultura familiar local sempre foi marginalizada, o que provocou seu estabelecimento em regiões do município impróprias para o cultivo do arroz, em território distante ao urbano (de $80 \mathrm{a} 100 \mathrm{~km}$ ), com limitação de acesso devido às estradas serem de chão (sem beneficiamento), dificultando o escoamento e a comercialização dos produtos. Desta forma, percebe-se a importância em desenvolver estratégias que arquem com o desenvolvimento local da agricultura familiar. Desenvolvimento local, segundo conceitua Borges (2007), é uma construção política que reivindica modificações em um modelo atual de gestão local e em concepção e comportamento da própria sociedade local. É importante ressaltar que local pode ser delimitado como bairros, municípios ou regiões, dependendo do autor (BARBOSA, 2018).

Dada a importância do trabalho da mulher e seu mérito relativizado pelas diferenças de gêneros impostas no sistema patriarcal, seu reconhecimento se torna um desafio. Portanto, estudos que evidenciem a participação laboral das mulheres nas atividades produtivas dentro da agricultura familiar são necessários. De acordo com o supracitado, o objetivo do presente trabalho é destacar o trabalho desenvolvido pelas mulheres na agricultura familiar no município de Itaqui - RS e demonstrar o protagonismo negado a elas.

Assim sendo, este trabalho buscou compreender as relações de trabalho e gênero existentes no meio rural e, com isso, identificar as diversas atividades laborais da mulher no campo, descrevendo seu trabalho remunerado e não remunerado e relatando o processo de desenvolvimento local com a participação da mulher.

\section{Procedimento metodológico}

O presente trabalho foi realizado como pesquisa qualitativa de caráter descritivo, cujo principal objetivo é descrever características de uma determinada população ou fenômeno (GIL, 2012). 
O público-alvo da pesquisa foram as mulheres agricultoras que atuam como feirantes no município de Itaqui - RS. Todas as agricultoras que estavam presentes no feirão foram convidadas a participar do estudo e responder ao questionário. Todas aceitaram participar, totalizando 12 mulheres. Importante esclarecer que elas são feirantes que participam do feirão que ocorre apenas uma vez ao mês (se difere das outras feiras, pois é maior e tem uma estrutura própria). As entrevistas foram realizadas no ambiente da feira do produtor, ocorrendo entre os intervalos de atendimento à clientela.

A coleta de dados consistiu na utilização de um questionário semiestruturado que teve como objetivo entender o espaço e protagonismo das mulheres agricultoras no processo de desenvolvimento da agricultura familiar do município de Itaqui.

A abordagem das feirantes para a aplicação do questionário se deu com a leitura do termo de consentimento, quando foi explicado o motivo da aplicação do questionário e os assuntos abordados, além de que, com sua concordância em participar, estaria autorizando a utilização dos dados (sem identificação) e colaborando para a realização do presente estudo. Ocorreu o aceite de participação por todas as feirantes, até porque existia um trabalho de cooperação, de acompanhamento e divulgação das feiras no ano de realização deste estudo, por parte de discentes e docentes da Universidade Federal do Pampa (UNIPAMPA)/Campus Itaqui. O questionário foi produzido com perguntas relevantes quanto a dados sociodemográficos, tais como: cor, idade, grau de escolaridade, estado civil e número de filhos. Para os dados econômicos, foram perguntas relacionadas aos trabalhos laborais com e sem renda e produção diária, bem como perguntas buscando identificar as atividades recreativas, associativas e religiosas. Ressalta-se que não foram solicitados os nomes das entrevistadas.

Posteriormente às entrevistas, iniciou-se a busca por referenciais bibliográficos que serviram de embasamento teórico acerca de conceitos como agricultura familiar, desenvolvimento local, destacando o trabalho desenvolvido pelas mulheres agricultoras e protagonismo negado a elas, além de suas especificidades teórico-metodológicas, ancorando a identificação das diferenças vivenciadas pelas mulheres na agricultura familiar no município de Itaqui - RS.

Com relação à análise dos dados, foi utilizado o programa EXCEL ${ }^{\circledR}$ (Microsoft Office Excel 2007) para a construção do banco de dados com as variáveis obtidas na pesquisa, e os resultados foram apresentados por meio de estatística descritiva.

\section{Resultados e discussão}

A agricultura familiar no município de Itaqui - RS ocupa uma área de 12.551ha, equivalente a 4,91\% do total da área utilizada nas atividades agrícolas e $51,8 \%$ das unidades de produção agrícola (CERETTA, 2013). Os dados mostram que existe maior número de estabelecimentos da agricultura familiar ocupando áreas menores, corroborando o que afirmam Ogassawara et al. (2016), que isso pode caracterizar uma atividade que historicamente permaneceu marginalizada, à sombra da produção orizícola e a pecuária de corte. Esse cenário não 
é apenas do município, mas é reflexo do modelo regional baseado na monocultura orizícola. A agricultura familiar no município de Itaqui-RS busca desenvolver-se através de estratégias para geração de renda, que consiste em atividades laborais na agropecuária, feira e elaboração de produtos artesanais, processados e in natura.

Em uma construção da definição e compreensão do processo de desenvolvimento local, Carvalho Filho (1999) entende que os protagonistas são atores locais que seguem uma estratégia de valorização das potencialidades locais, em um processo de construção coletiva que impulsiona um novo padrão de crescimento econômico que contrarie as lógicas de exclusão socioeconômica e política. Desenvolvimento local está relacionado à capacidade de organização dos atores, utilizando potencialidades do local para se desenvolver (BARBOSA, 2018). Nesse contexto, as formas de organização das mulheres na agricultura familiar em Itaqui, de acordo com as entrevistas realizadas, têm como objetivo a integração em prol das comunidades onde suas famílias estão inseridas, articulando a dimensão econômica, social e cultural de eficiência do seu trabalho, exercendo um papel mobilizador na representação social, contribuindo para o desenvolvimento da sua localidade (Tabela 1).

Tabela 1 - Variáveis sociodemográficas e participação social das agricultoras de Itaqui-RS, 2019 (n=12).

\begin{tabular}{lc}
\hline Variáveis & $\mathbf{N}(\mathbf{\%})$ \\
\hline Idade & $2(16,6)$ \\
$\mathbf{1 8 - 3 0}$ & $1(8,3)$ \\
$\mathbf{3 1 - 4 5}$ & $5(41,6)$ \\
$\mathbf{4 6 - 6 0}$ & $4(33,5)$ \\
$\mathbf{6 0 0}$ & \\
Filhos & $2(16,6)$ \\
$\mathbf{0}$ & $3(24,9)$ \\
$\mathbf{1}$ & $3(24,9)$ \\
$\mathbf{2}$ & $2(16,6)$ \\
$\mathbf{3}$ & $2(16,6)$ \\
$\mathbf{5}$ & \\
Situação Conjugal & $10(83,4)$ \\
Casada ou com companheiro & $2(16,6)$ \\
Solteira ou sem companheiro & \\
Participação Social** & $7(58,3)$ \\
Lazer & $7(58,3)$ \\
Igreja & $8(66,6)$ \\
Centro comunitário & $12(100)$ \\
Associações & \\
\hline
\end{tabular}

* Questão de múltipla escolha.

Fonte: Elaborado pelas autoras a partir das entrevistas com as agricultoras, 2019. 
A faixa etária das mulheres entrevistadas (Tabela 1) mostra que 74\% possuem mais de 45 anos. Em região do oeste do Estado de Santa Catarina, Alves (2016) observou a presença de poucas mulheres jovens, sendo que a maioria apresentava idades entre 50 e 60 anos. Konzen e Areosa (2019) descrevem que, no processo de envelhecimento no meio rural, há diferenças entre homens e mulheres que contribuíram para o empobrecimento e a saída do campo. Os direitos trabalhistas voltados para as mulheres levam mais tempo porque as notas são emitidas em nome do homem. No entanto, o direito à aposentadoria para as mulheres agricultoras sempre foi uma reivindicação dos movimentos sociais. Em 2004, foi criado o Programa Nacional de Documentação da Mulher Trabalhadora Rural, o que facilitpu a aposentadoria e contribuiu para o desenvolvimento rural (KONZEN; AREOSA, 2019).

As 12 mulheres têm um total de 25 filhos, dentre os quais apenas 8 moram ainda nas propriedades. Com relação à permanência no campo, pode-se observar dois extremos: 2 entrevistadas não têm filhos e 2 têm 5 filhos, sendo que apenas um mora na propriedade com os pais, ocasionando, de qualquer forma, problema na sucessão geracional. Para Jahn (2013), o envelhecimento no campo causa problemas na sucessão familiar, enquanto os jovens vão para as cidades em busca de educação e renda e os pais permanecem no campo, as mulheres, mesmo envelhecendo, continuam fazendo uma luta silenciosa de resistência, preservando e reproduzindo saberes populares na produção de alimentos.

Os movimentos sociais organizados no município são o Sindicato de Trabalhadores Rurais e Associação dos Produtores da Agricultura Familiar de Itaqui - APAFI. Embora não exista uma instituição formada apenas por mulheres, elas participam de diversas atividades em outras organizações (Tabela 1), sendo que 66,6\% participam de atividades religiosas, $100 \%$ de associações e $74,9 \%$ de atividades em centro comunitário.

Van Der Schaaf (2003), em uma contextualização histórica dos movimentos sociais no Rio Grande do Sul, destaca o papel das mulheres em mobilizações que são organizadas a partir do movimento feminino de igrejas e sindicatos. O conceito de que cabe à mulher tudo o que é reprodutivo contribui para a invisibilidade do seu trabalho na agricultura, e embora as agricultoras se mobilizem, articulando-se em suas comunidades, ainda existe a carência de um movimento feminino, de uma agremiação organizada que represente seu espaço e seja formada somente por essas mulheres. A partir desta representação social, várias demandas poderiam ser levantadas e conquistadas por meio de políticas públicas existentes.

A partir das entrevistas, buscou-se distinguir as atividades remuneradas e não remuneradas desenvolvidas pelas agricultoras do município de Itaqui, em denotação ao cotidiano, a fim de mensurar sua contribuição para o desenvolvimento da propriedade e comunidade em que estão inseridas (Tabela 2). 
Tabela 2 - Distribuição quanto à remuneração, quanto ao tempo empregado e à contribuição na renda da família, conforme atividade e produto. Agricultoras familiares (n=12) de Itaqui-RS, 2019.

\begin{tabular}{|c|c|c|c|c|c|}
\hline $\begin{array}{l}\text { Quanto à } \\
\text { remuneração }\end{array}$ & $\begin{array}{l}\text { Tipo de } \\
\text { atividade }\end{array}$ & Produtos & $\begin{array}{c}\text { Meio de } \\
\text { comercialização }\end{array}$ & $\begin{array}{c}\text { Tempo estimado } \\
\text { de preparação/ } \\
\text { produção/ } \\
\text { comercialização }\end{array}$ & $\begin{array}{c}\text { Remuneração } \\
\text { estimada em } \\
\% \text { na renda }\end{array}$ \\
\hline \multirow{5}{*}{ 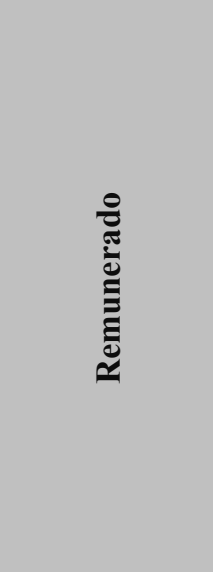 } & Avicultura & Ovos & Feira & $\begin{array}{c}1 \text { dia ao mês } \\
\text { comercialização }\end{array}$ & 15 \\
\hline & $\begin{array}{l}\text { Agroindústria } \\
\text { de panificados }\end{array}$ & $\begin{array}{l}\text { Pães, cucas, } \\
\text { bolos }\end{array}$ & PAA e PNAE & $\begin{array}{c}1 \text { dia da semana } \\
\text { produção }\end{array}$ & 30 \\
\hline & Bovino de leite & $\begin{array}{l}\text { Leite, doce de } \\
\text { leite e rapaduras }\end{array}$ & Feira & $\begin{array}{l}1 \text { dia ao mês } \\
\text { produção }\end{array}$ & 15 \\
\hline & $\begin{array}{l}\text { Plantio, } \\
\text { manejos }\end{array}$ & $\begin{array}{l}\text { Abóbora, } \\
\text { mandioca, } \\
\text { batata-doce e } \\
\text { tempero verde }\end{array}$ & Feira e PNAE & $\begin{array}{l}2 \text { horas/dia } \\
\text { preparação }\end{array}$ & 20 \\
\hline & $\begin{array}{l}\text { Processamento } \\
\text { mínimo }\end{array}$ & $\begin{array}{l}\text { Compotas e } \\
\text { verduras }\end{array}$ & Feira & $\begin{array}{l}\text { 4h/quinzena } \\
\text { produção }\end{array}$ & 20 \\
\hline \multirow{5}{*}{ 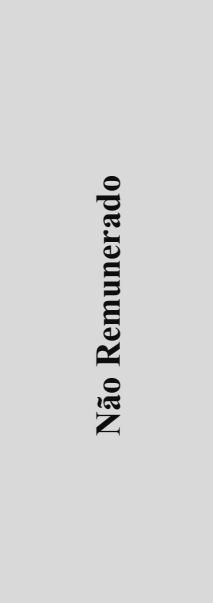 } & $\begin{array}{l}\text { Afazeres } \\
\text { domésticos }\end{array}$ & $\begin{array}{l}\text { Limpeza do } \\
\text { lar e pátio }\end{array}$ & $* *$ & $2 \mathrm{~h} / \mathrm{dia}$ & $* *$ \\
\hline & $\begin{array}{l}\text { Cuidados com } \\
\text { os filhos }\end{array}$ & $\begin{array}{l}\text { Lavar roupas e } \\
\text { preparação dos } \\
\text { alimentos }\end{array}$ & $* *$ & $3 \mathrm{~h} / \mathrm{dia}$ & $* *$ \\
\hline & Administração & $\begin{array}{l}\text { Organização } \\
\text { do orçamento } \\
\text { doméstico }\end{array}$ & $* *$ & 1h/mês & $* *$ \\
\hline & $\begin{array}{l}\text { Horta } \\
\text { doméstica }\end{array}$ & $\begin{array}{l}\text { Manejo e } \\
\text { manutenção }\end{array}$ & $* *$ & 3h/semana & $* *$ \\
\hline & $\begin{array}{l}\text { Cuidados com } \\
\text { animais } \\
\text { domésticos }\end{array}$ & $\begin{array}{l}\text { Alimentação } \\
\text { e cuidados } \\
\text { veterinários }\end{array}$ & $* *$ & 1h/semana & $* *$ \\
\hline
\end{tabular}

PAA = Programa de Aquisição de Alimentos, PNAE= Programa Nacional de Alimentação Escolar.

Fonte: Elaborado pelas autoras a partir das entrevistas, 2019.

Pode-se observar que o tempo empregado nas atividades remuneradas e não remuneradas se equivalem, ainda que não haja um rendimento financeiro para essas atividades, sendo que toda atividade não remunerada é de responsabilidade das mulheres. Bojanic (2017), em seu trabalho sobre as mulheres, aponta que são elas as responsáveis pela maior parte do trabalho não remunerado, ou seja, ficam à frente de todo trabalho reprodutivo, o que limita significativamente a capacidade de cooperar com a produção agrícola. 
A mulher sempre teve suprimido o reconhecimento do seu trabalho produtivo, apesar de, no campo, encarar uma tríplice jornada, que se deve à sobrecarga proveniente do acúmulo de funções, e ainda suporta a desigualdade imposta pela diferença de gênero, o que inviabiliza o seu trabalho e inferioriza a sua atuação enquanto protagonista no processo de desenvolvimento local (OLIVEIRA, 2007). Com a invisibilidade do trabalho das mulheres, não existe o reconhecimento social da profissional agricultora, uma vez que a atividade realizada cotidianamente na esfera doméstica é naturalizada como dever e não tem seu reconhecimento na produção da renda na família.

Conforme as entrevistadas, os meios de comercialização dos produtos da agricultura familiar no município geralmente são por meio de circuitos de comercialização curto, em feiras, PNAE e PAA (Tabela 2). O circuito de comercialização curto do qual os agricultores se utilizam no município envolve a cadeia produtiva agroalimentar de pequeno porte, com representatividade e com diferenciais em seus produtos. Geralmente, a comercialização é realizada em feiras, entregues no município, atravessadores e direto com o cliente. $\mathrm{O}$ circuito tem uma representação territorial que gera valor agregado e reforça a especificidade do meio rural, valorização social e cultural dos produtos, como a maneira de produção (SILVEIRA, 2009).

Os produtos apresentados na Tabela 2 são artesanais ou com processamento mínimo (panificados, queijo, compotas, rapaduras); hortaliças (mandioca, batata doce, abóbora, salsinha, cebolinha, pepino, couve, alface, milho); animais de criação (leite, ovos). Todos os produtos artesanais vendidos na feira são resultado do trabalho praticamente apenas das agricultoras, sendo que algumas relataram a ajuda de seu cônjuge. De Mesquita e Mendes (2012) analisam o trabalho das mulheres agricultoras e sua importância para a dinâmica não apenas reprodutiva, mas produtiva do estabelecimento rural, sendo responsáveis por diversas atividades relacionadas à manutenção da propriedade, tanto na lavoura junto ao companheiro como com cuidados com a criação e a manutenção do lar.

Um fato importante que cabe ser ressaltado é que três agricultoras se organizaram e fundaram uma agroindústria familiar de panificados "Niholi", na qual elas reservavam um período por semana para produzir os panificados que eram entregues no PNAE, para alimentação escolar, e também comercializados na feira. Essa iniciativa foi um marco para a agricultura familiar, sendo que, atualmente, outra agricultora, juntamente com sua filha, organizou outra agroindústria de panificados "Doce Lar", com os mesmos propósitos da agroindústria anterior. As duas agroindústrias, atualmente, estão diversificando a produção, incluindo pães recheados, tortas, salgados e doces para aniversário.

As agroindústrias no interior acabam facilitando a dinâmica do mercado no meio rural, isso porque essas localidades ficam distantes da cidade. A agroindustrialização na agricultura familiar interage com diferentes tipos de redes, o que implica estratégias diferenciadas para regiões marginalizadas. A estratégia é adotada em função do desenvolvimento de uma produção especializada, ajustando-se a diferentes áreas rurais. Mior (2007) estabelece, em sua pesquisa, que mais de $80 \%$ do valor da produção foi produzido por estabelecimentos agropecuários com menos de 50 hectares. Em concordância com a forma como a agricultura familiar utiliza de estratégias para sobrevivência, De Mesquita e Mendes (2012) descrevem 
o trabalho feminino também como uma estratégia, que contribui de maneira significativa para a sobrevivência da família.

Outro fato importante é que as agricultoras participam de Palestras e Cursos de Boas Práticas de Produção, Conservação e Comercialização de Alimentos, pois a legislação atual impede que uma série de produtos, principalmente de origem in natura, sejam comercializados sem que haja algum tipo de processamento mínimo. Geralmente, esses cursos e palestras aos agricultores são ministrados em parceria entre Universidade Federal do Pampa (UNIPAMPA), Empresa de Assistência Técnica e Extensão Rural (EMATER) e a Secretaria Municipal da Agricultura. Os cursos e palestras têm por finalidade apresentar e ensinar as técnicas de processamento em conformidade com a legislação, bem como práticas de manejos com a agropecuária. A participação por parte das agricultoras é maior que a dos agricultores, e isto se explica devido à mulher ser responsável por atividades não remuneradas, além do empenho em buscar informações e se manterem atualizadas.

As entrevistadas distribuem seu tempo em diversas atividades (Tabela 2), sendo que $50 \%$ delas são aposentadas e relataram ter sua atividade reduzida no plantio. No entanto, nas demais funções, como cuidar da criação, horta, afazeres domésticos e feiras, elas são as responsáveis. Outras 33\% responderam trabalhar com o cônjuge na plantação, quando não ficam responsáveis por todo trabalho nas propriedades, isso porque muitas vezes os agricultores trabalham em lavouras de arroz (Oryza sativa). Evidencia-se, novamente, que todo o trabalho não remunerado é realizado pelas mulheres e não tem seu reconhecimento na sociedade, devido ao seu papel seminal no trabalho reprodutivo (doméstico e de cuidado), exercido exclusivamente por mulheres (FARIA, 2009).

O preconceito estabelecido na sociedade é que cabe à mulher cuidar da casa, filhos e marido; e, no entanto, a atividade agropecuária passa a ser uma extensão do seu papel de mãe e dona de casa, sendo atividades principalmente exercidas pelas mulheres, marcando a distinção desigual de gênero no mundo rural (PEREIRA, 2015).

Alves (2016), em sua tese, apresenta dados de sua pesquisa que tornam evidente a ausência masculina no trabalho reprodutivo, o que colabora para a naturalização da distinção de gênero, ou seja, existe uma aceitação, por parte da mulher, de que, não obstante o trabalho na lavoura seja compartilhado por entre iguais, os afazeres domésticos ficam unicamente a cargo dela. Herrera (2019) apresenta dados parecidos relacionando a inexpressiva participação dos homens em trabalhos no núcleo familiar, reafirmando, assim, a estereotipação, e contribuindo para a sobrecarga e tríplice jornada de trabalho.

Com relação à comercialização dos produtos, é importante ressaltar que $80 \%$ dos feirantes que participam da feira do produtor em Itaqui são mulheres. Esse dado reforça que o trabalho da mulher agricultora deve ser considerado em seus diversos aspectos remunerados ou não (produtivo e reprodutivo), dando visibilidade à sua atuação no processo de desenvolvimento da agricultura familiar.

Quanto ao espaço da mulher na família, comunidade e agricultura, sempre esteve sujeitado ao protagonismo geracional transmitido ao homem, cabendo à mulher muito trabalho e 
nenhum reconhecimento, embora seja incontestável a participação ativa da mulher na geração de renda da família. Varroto (2017), em seu artigo, contextualiza que a mulher foi mantida distante dos processos de protagonismos sócio-históricos, excluindo-a de diversos espaços da sociedade e deixando-a à sombra da história.

Já para Nascimento (2018), a sociedade definiu os espaços destinados aos homens e às mulheres e como a interferência da distinção entre os gêneros tem implicado na organização da divisão desses espaços, uma vez que, para os homens, tende-se a destinar prioritariamente o trabalho produtivo, voltado ao espaço público, e às mulheres o trabalho reprodutivo, voltado preponderantemente ao espaço privado. Essa explicação elimina o conjunto, uma vez que todos se inserem nele, mas de formas diferenciadas na produção e reprodução.

As mulheres agricultoras se desdobram na realização da tríplice jornada de trabalho, renunciando tempo para cuidarem de si mesmas. E quando perguntadas sobre o que gostariam de fazer se tivessem um tempo disponível para si, sem a família, uma delas respondeu: "Minha vontade era fazer um curso superior"; outra disse: "Gostaria de ir ao salão de beleza, ficar mais bonita". No entanto, a maioria incluiu a família nesse tempo. Com esses relatos, percebe-se que a mulher não faz mais distinção entre os espaços, sendo a família em primeiro lugar, em uma renúncia constante de si mesma, deixando seus desejos para o último momento, que nunca chega.

Nos dados do IBGE (2010), a ocupação das mulheres nas atividades agropecuárias no município de Itaqui corresponde a $23,7 \%$ e dos homens $76,2 \%$. Já os dados que contabilizam a população residente no campo, as mulheres representam $43,9 \%$, enquanto os homens $56,1 \%$. Isso mostra que, apesar de representar menos de um terço na ocupação das atividades no campo, o percentual de mulheres que residem no meio rural é quase equivalente ao dos homens. É importante mencionar que, para caracterizar como ocupação em atividade agropecuária, deve-se estabelecer contrato de carteira assinada ou bloco de produtor, o que ajuda na invisibilização dessas mulheres. Outro ponto a considerar é que a principal atividade agrícola do município é orizícola, e na pecuária, é com bovinos de corte, sendo atividades praticamente realizadas apenas por homens. Os dados da Comissão Nacional de Mulheres Trabalhadoras Rurais da CONTAGE apresentam que as mulheres respondem por $40 \%$ da mão de obra rural, sendo que, na agricultura familiar, elas representam $36,2 \%$ das pessoas ocupadas (ABRAMOVAY; SILVA, 2000).

Em uma concepção sobre a mulher e seu espaço, Van Der Shaaf (2003), em suas pesquisas, discorre como a modernização alterou a organização dos pequenos estabelecimentos e a posição social da mulher, ocorrendo a perda da autoridade masculina, o que teve uma enorme influência no espaço da mulher. Essas mudanças já são percebidas na região de Itaqui, pois, conforme as entrevistadas, todas afirmaram ter participação nas questões administrativas da propriedade. Uma agricultora declarou: "Tudo que diz respeito à compra e venda é uma decisão tomada em conjunto" (Agricultora Associada à APAFI). Contudo, existe um longo caminho até a mulher ter o seu reconhecimento na agricultura familiar local. 


\section{Considerações finais}

Por meio deste estudo, foi possível destacar o trabalho desenvolvido pelas mulheres agricultoras nos trabalhos produtivos que geram renda direta e indireta para a manutenção da família, pela comercialização de produtos cultivados e processados, bem como pela criação de animais. Foram destacados, também, os trabalhos reprodutivos, com a manutenção do núcleo familiar, bem como na representação de suas famílias em reuniões com técnicos da EMATER, da Secretaria Municipal da Agricultura de Itaqui, nas associações, articulando-se com lideranças; em palestra, buscando informações e aperfeiçoamento profissional para melhorar a apresentação dos seus produtos.

Pode-se observar que a participação dessas agricultoras feirantes nos mais variados âmbitos sociais tem contribuído significativamente no processo de transformação da agricultura familiar, através da visibilidade dada aos produtores, uma vez que a agricultura familiar no município de Itaqui é, historicamente, tida como marginalizada.

Ainda, é importante destacar a tríplice jornada de trabalho encarada tanto em atividades reprodutivas como produtivas, que por vezes sobrecarrega as mulheres. Contudo, neste artigo é tratado como protagonismo, uma vez que elas assumem para si a responsabilidade de trabalhar nas diversas esferas, constatando-se, dessa forma, sua marcante atuação na manutenção das famílias no campo e no desenvolvimento da agricultura familiar de Itaqui.

Por fim, deve-se considerar a ampliação do espaço da mulher no campo como resultado das lutas dos movimentos organizados e construídos a partir de conquistas sociais. Porém, para que ocorram maiores avanços na sociedade, é necessário modernizar conceitos e desconstruir o patriarcalismo, dando voz às mulheres e tornando visível todo o seu trabalho produtivo e o impacto no desenvolvimento dessas propriedades, pois mesmo que tenha sido omitido às mulheres a valorização do seu trabalho, isso não inviabilizou sua luta, pois continuam desbravando novos espaços e construindo o protagonismo feminino no campo.

\section{Referências}

ABRAMOVAY, M.; SILVA, R. da. As relações de gênero na Confederação Nacional de Trabalhadores Rurais (CONTAG). Trabalho e gênero: mudanças, permanências e desafios, v. 34, p. 347-366, 2000.

ALVES, N F. Ressignificação dos papéis sociais de mulheres na agricultura familiar de base agroecológica. Dissertação (Mestrado em Agroecossistemas) - Universidade Federal de Santa Catarina, Florianópolis, 2016. 138 f.

ALVES, G.S.; SELL, L.B.; CASTRO, A.M. O trabalho da mulher no campo e suas invisibilidades. Revista SURES, n. 11, 2018. 
BALESTRIN, J. A relevância do PRONAF na agricultura familiar: Perspectiva e importância do programa desde sua criação. Trabalho de Conclusão de Curso (Bacharel em Economia) - Universidade Federal do Rio Grande do Sul, Porto Alegre, 2010. 65 f.

BOJANIC, A. A importância das mulheres rurais no desenvolvimento sustentável do futuro. Organização das Nações Unidas para Alimentação e Agricultura (FAO), 2017. Disponível em: https://nacoesunidas.org/artigo-a-importancia-das-mulheres-rurais-nodesenvolvimento-sustentavel-do-futuro/. Acesso em: 03 jan. 2019.

BARBOSA, T.N. Desenvolvimento local: uma análise crítica dos paradigmas e dos impasses. Dissertação (Mestrado em Ciência Política) - Universidade Federal de São Carlos. São Carlos, 2018. 103f.

BORGES, C.M. Desenvolvimento local e avaliação de políticas públicas: Análise de viabilidade para construção de um índice de Desenvolvimento Local para o Município de São José do Rio Preto. Dissertação (Mestrado Administração de Organizações) Universidade de São Paulo, Ribeirão Preto, 2007. 2016 f.

BRUMER, A.; DOS ANJOS, G. Gênero e reprodução social na agricultura familiar. Revista Nera, Presidente Prudente, v. 11, n. 12, p. 6-17, 2008.

BRUMER, A.; PAULILO, M.I. As agriculturas do sul do Brasil. Revista Estudos Feministas, v. 12, n. 1, p. 171-174, 2004.

CARVALHO FILHO, M.V. Assessoria ao processo de desenvolvimento local. Rio Grande do Norte. Projeto de Cooperação Técnica-INCRA-IICA, 1999.

CERETTA, J.V. Evolução e diferenciação dos sistemas agrários de Itaqui-RS: As decorrências á produção e beneficiamento do arroz. Monografia (Tecnólogo em Desenvolvimento Rural) - Faculdade de Ciências Econômicas da Universidade Federal do Rio Grande do Sul, Porto Alegre, 2013. 76f.

CERETTA, J.V.; DAL FORNO, M.A.R.; BERRETA, M. dos S.R.; WIVES, D.G.; FIGUEIREDO, L.S. Desenvolvimento rural e economia local: evolução e diferenciação dos sistemas agrários e o surgimento e a consolidação da rizicultura no município de Itaqui. COLÓQUIO-Revista do Desenvolvimento Regional, v. 11, n. 1, p. 121-148, 2014.

DE MESQUITA, L.A.P.; MENDES, E. de P.P. Mulheres na agricultura familiar: a comunidade Rancharia. Campo Alegre de Goiás, 2012.

FARIA, N. Economia feminista e agenda de lutas das mulheres no meio rural. In: BUTTO, A. (Org.) Estatísticas Rurais e a Economia Feminista: Um olhar sobre o trabalho das mulheres. Brasília: MDA, 2009. 
GIL, A.C. Como elaborar projetos de pesquisa. 4. ed. São Paulo: Atlas, 2002.

HERRERA, K.M. A jornada interminável: a experiência no trabalho reprodutivo no cotidiano das mulheres rurais. Tese (Doutorado em Sociologia Política) - Universidade de Santa Catarina, Florianópolis, 2019. 227p.

HERRERA, K.M. Repensando o valor social do trabalho das mulheres rurais. In: SEMINÁRIO INTERNACIONAL FAZENDO GÊNERO, 13., 2017, Florianópolis. Anais [...] Florianópolis, 2017.

IBGE. Instituto Brasileiro de Geografia e Estatística. Panorama. 2021. Disponível em: https://cidades.ibge.gov.br/brasil/rs/itaqui/panorama. Acesso em: 10 jan. de 2021.

JAHN, E. de F. Envelhecimento do campo e o movimento de mulheres camponesas: desafios e perspectivas. Revista Grifos, n. 34/35, p. 113-132, 2013.

KONZEN, L.T.; AREOSA, S.V. Gênero e os desafios do envelhecimento no meio rural. In: SEMINÁRIO INTERNACIONAL DEMANDAS SOCIAIS E POLÍTICAS PÚBLICAS NA SOCIEDADE CONTEMPORÂNEA, 26., 2019, Santa Cruz do Sul. Anais [...] Santa Cruz do Sul, 2019.

MIOR, L.C. Agricultura familiar, agroindústria e desenvolvimento territorial. In: COLÓQUIO INTERNACIONAL DE DESENVOLVIMENTO RURAL SUSTENTÁVEL. 2007, Florianópolis. Anais [...] Florianópolis, 2007.

NASCIMENTO, A.C.; ROCHA, R.G.; MENDONÇA, M.R. Movimentos contrahegemônicos: o papel da mulher na agricultura campesina. InterEspaço: Revista de Geografia e Interdisciplinaridade, v. 3, n. 10, p. 214-233, 2018.

NIEDERLE, P.A.; FIALHO, M.A.V.; CONTERATO, M.A. A pesquisa sobre agricultura familiar no Brasil - aprendizagens, esquecimentos e novidades. Revista de economia e sociologia rural, v. 52, p. 9-24, 2014.

OGASSAWARA, J.F.; SILVEIRA, P.R.C. da; NEVES, J.A.S das. Os Efeitos do PAA sobre a Agricultura Familiar de Itaqui/RS. In: ENCONTRO DA REDE DE ESTUDOS RURAIS, 7., 2016, Natal, Anais... Natal, RN, 2016.

OLIVEIRA, P.R.C; LELIS, C.T.; SILVA, K.A.; VIEIRA, T.B.; LORETO, M. das. D.S. Agricultura familiar e as relações de gênero: um estudo da trajetória da mulher na agricultura familiar. In: SEMANA ACADÊMICA DA FDV, 2007, Viçosa. Anais [...] Viçosa, 2007.

PEREIRA, R.S. Abordagem teórica sobre a questão de gênero e desenvolvimento rural: dos projetos assistenciais ao planejamento de gênero. In: STADUTO, J. A. R.; Souza, M.; 
NASCIMENTO, C. A. Desenvolvimento Rural e Gênero: abordagens analíticas, estratégias e políticas públicas. Porto Alegre: UFRGS, 2015. p. 17-41.

PILLAR, V. de P. et al. Campos Sulinos: conservação e uso sustentável da biodiversidade. Brasília: Ministério do Meio Ambiente, 2009.

SILVEIRA, P.R.C. da.; BALEM, T.A.; DONAZZOLO, J.; SILVA, G.P. da. A construção dos mercados na produção artesanal de alimentos: os circuitos curtos de comercialização. In: CONGRESSO BRASILEIRO DE SOCIOLOGIA, 14., 2009, Rio de Janeiro. Anais [...] Rio de Janeiro, 2009.

SOIHET, R.; SOARES, R.M.A.; COSTA, S.G. A história das mulheres. Cultura e poder das mulheres: ensaio de historiografia. Revista Gênero, v. 2, n. 1, 2001. Disponível em: https://periodicos.uff.br/revistagenero/article/view/30986. Acesso em: 20 set. 2020.

VAN DER SCHAAF, A. Jeito de mulher rural: a busca de direitos sociais e da igualdade de gênero no Rio Grande do Sul. Sociologias, v. 5, n. 10, p. 412-442, 2003. Disponível em: < https://seer.ufrgs.br/sociologias/article/view/5437>. Acesso em: 15 set. 2020.

VAROTTO, D.P. Agroecologia e gênero: perspectivas para a emancipação das mulheres e a agricultura familiar. RELACult-Revista Latino-Americana de Estudos em Cultura e Sociedade, v. 3, n. 3, 2017. Disponível em: <https://periodicos.claec.org/index.php/relacult/article/view/859/465>. Acesso em: 12 out. 2020. 